\title{
Visual and phonological pathways to the lexicon: Evidence from Chinese readers
}

\author{
K. J. LECK, B. S. WEEKES, and M. J. CHEN \\ Australian National University, Canberra, Australia
}

\begin{abstract}
In this study, we investigated the role of visual and phonological information in lexical access of Chinese characters. Homophonic English words have been the main source of stimuli for word recognition research. However, since these stimuli also often look alike, visual and phonological information may be confounded in reported experiments. In contrast, many homophonic Chinese characters are visually distinct. In addition, visually similar characters often have very different pronunciations. These characteristics allow a more controlled investigation of the roles of visual and phonological information in activation of meaning. In the present study, two types of Chinese characters were used in a semantic categorization paradigm: integrated characters, which contain strokes that are not separable; and compound characters, which contain at least two clearly identifiable components. The results show that the recognition of a Chinese integrated character depends primarily on visual information, whereas the recognition of a Chinese compound character relies on visual, phonological, and semantic information. It is concluded that visual information plays a greater role in Chinese character recognition than has previously been documented.
\end{abstract}

Is visual or phonological information the key to lexical access? This question has been explored extensively with respect to English words, but less is known about the lexical access of Chinese characters. It is well known that there are robust phonological interference effects on the recognition of English words. This suggests that phonological information has a dominant role in lexical access (Van Orden, 1987). However, because orthographic and phonological information are confounded in English, it is unclear whether these interference effects are simply due to phonology alone. By using a different type of orthography, such as Chinese, we may be able to test more sensitively the influence of visual and phonological processing in word recognition.

All printed words are primarily visual patterns which can be decomposed into separate identifiable components. When our perceptual system processes a word, it is reasonable to suppose that the individual components (e.g., letters) are recognized first before the whole word is finally assembled. These components (if meaningful to the system) might therefore play a role in lexical access. Current theories of word recognition differ in the extent to which visual and phonological information are assumed to lead to lexical access. In some models, visual information is assumed to be involved in lexical access (Coltheart, 1978; Paap \& Noel, 1991; Seidenberg, 1985; Seidenberg \& McClelland, 1989; Taft, 1991). For example, the dual-route theory proposes that there are two in-

This work was completed with a Pacific Cultural Foundation subsidy (PCF-93-1057). Correspondence should be addressed to M. J. Chen, Department of Psychology, School of Life Sciences, Australian National University, Canberra, P. O. Box 4, ACT 0200, Australia (e-mail: may-jane.chen@anu.edu.au). dependent routes to lexical access: a direct visual route and an indirect phonological route (e.g., Coltheart, Curtis, Haller, \& Atkins, 1993). The direct visual route, which is based solely on the processing of the visual features of a word, is the primary means to lexical access for skilled readers and for familiar words. The indirect phonological route is employed only when lexical access via the direct visual route is slow. This occurs, for example, during the reading of nonwords and low-frequency words. The parallel distributed processing (PDP) model (Seidenberg \& McClelland, 1989) proposes that, instead of the two routes' being independent of each other, both the visual and the phonological pathways interact within a distributed network to activate the mental representation of a stimulus word. However, in similarity with the dual-route theory, the PDP model also proposes that the computation of phonology lags behind visual analysis (since it is the visual features that are extracted first). Consequently, for a large number of common words, sufficient orthographic information will have been extracted from the stimulus input to permit identification prior to the accrual of enough phonological information for identification.

A third model questions the propositions of both the dual-route and the PDP models by asserting that the phonological route predominates over the direct visual route (Van Orden, 1987; Van Orden, Johnston, \& Hale, 1988; Van Orden, Pennington, \& Stone, 1990). In this account of word recognition, phonology computed from the individual component letters of a stimulus word is directly employed for lexical access. However, because many words in a language are homophones (e.g., seen-scene), a pool of all possible candidates with the same pronunciation will also be activated. Consequently, a verification check back to the visual input pattern needs to be performed in 
order for one of the activated representations to be selected. In this model, the final assembled visual representation of a word plays a subsidiary role in lexical access.

\section{Evidence for the Visual Position}

It has been difficult to demonstrate that words are accessed directly via a visual route. The evidence has come from negative findings in the reading literature (Van Orden et al., 1990; Lukatela, Lukatela, \& Turvey, 1993). On the one hand, when an explicit phonological manipulation fails to affect word recognition, it is interpreted as evidence that word recognition proceeds primarily by the direct visual route; on the other hand, when an explicit phonological manipulation succeeds in affecting word recognition, it is interpreted as evidence that word recognition must have proceeded by the direct visual route at a pace equal to or slower than the phonological route.

\section{Evidence for a Phonological Position}

Van Orden et al. (1988), using a semantic categorization task, found very strong evidence in support of a role for computed phonology in accessing the meaning of a word. Subjects were presented with a category (e.g., an article of clothing) and were asked to judge whether a pseudohomophone sute (homophone for suit) was a member of the category. The results showed that the false positive error rate for pseudohomophones $(21.3 \%)$ was significantly greater than the false positive error rate for spelling controls such as surt (3\%). Since pseudohomophones are not represented in the lexicon, Van Orden and colleagues concluded that computed phonology was responsible for the observed interference effect. Homophonic words were found to show the same pattern of results as that for the pseudohomophones (the error rate in the homophonic word condition was $21.8 \%$, whereas it was $2.3 \%$ in the word spelling control condition). This result was interpreted as indicating that all pronounceable stimuli were processed similarly and that computed phonology might therefore be generally used in the activation of a word's meaning.

In his seminal experiment, Van Orden (1987) used a homophonic foil (e.g., rows) for the correct categorical exemplar (rose) and a visually similar word to the foil (robs) as the control. The visual similarity between rose (a target exemplar), rows (a homophonic foil), and robs (a visual control) is obvious. This example typifies the concern expressed earlier about the confound between spelling and pronunciation in English which hampers our investigation of the involvement of the visual information in word recognition with the English materials. In contrast, the orthographic and linguistic features of the Chinese language provide us with an excellent opportunity to investigate the ways visual and phonological information affect word recognition. There are at least two types of Chinese character: integrated, and compound. Integrated characters consist of strokes that criss-cross each other, are inseparable (e.g., 大), and have pronunciations that are often learned by rote. Compound characters consist of identifiable components (e.g., 洞). Among the compound characters, the most prevalent form is the phonetic-logographic compound, which has been estimated to comprise about $80 \%$ of all modern Chinese characters (see Li, 1977). Each compound character consists of two components, one of which conveys information about pronunciation of the character (the phonetic) and the other of which conveys information about the character's semantic category (the radical). For example, the character (pronounced "hu," meaning fox) has two components. The phonetic half (瓜) provides information about pronunciation of the character, while the radical half $(x)$ confers information about the character's semantic category. In this study, two criteria were used to differentiate between compound and integrated characters: (1) visual separability of the two components (radical and phonetic) and (2) presence or absence of a radical. If both criteria were met, a character was defined as compound. If neither criterion was met, a character was defined as integrated. Integrated characters therefore do not contain a semantic radical or a phonetic component.

The phonological information contained in a compound character, although not always consistent and reliable (see Yin, 1991), can be isolated and its effects on Chinese word recognition examined. Two features of the Chinese language are relevant to this: First, the Chinese language has many homophones, which are often very different in both appearance and meaning (e.g., 吾 and 潘 are both pronounced "wu," but 吾 means $I$ or $m e$ and 舞 means to dance); second, characters that look alike can have totally different pronunciations and meaning (e.g., 理 is pronounced as "li," meaning to reason, whereas 埋 is pronounced as "mai," meaning to bury). Given these characteristics, it is possible to manipulate the visual and phonological features of a word independently and to examine their separate effects on word recognition. The presence of the radical ( $)$ ) in a Chinese character tells a reader that the character is likely to be an animal name. There are other radicals which also signify animals (e.g., 羊, 马, 牛). Any character that bears one of these radicals is likely to be an animal name. However, it should also be noted that the information provided by a radical component is not wholly reliable or consistent. This allows us to construct foils that contain the radical component, but that are not members of the category that the radical signifies (e.g., 猜, "cai," meaning to guess).

One study of the relative importance of visual information in recognition of Chinese characters was reported by Biederman and Tsao (1979). They investigated the amount of interference experienced by Chinese readers during performance on a Stroop task. In their study, a Chinese color name written in an incompatible color of ink (e.g., the Chinese character for green was written in red ink) was presented to subjects. The task was to ignore the Chinese character and to name the color of the ink as quickly as possible. The results showed that the color-naming latencies of Chinese subjects were more impeded by the incompatible Chinese character than those of English subjects who performed an English version of the same task. The greater delay in the naming of 
colors demonstrated by Chinese subjects was interpreted as showing that the naming of colored inks and the reading of Chinese characters require visual processing, probably more than does the reading of English words. Thus, the presence of Chinese characters produced greater interference in the naming of colored inks than did the presence of English words. This finding, however, has not been consistently replicated in more recent studies (Tzeng \& Hung, 1988).

In the present study, we examined the role of visual and phonological information in semantic categorization of Chinese characters by using Van Orden's (1987) semantic categorization paradigm. Two types of Chinese characters (compound and integrated characters) were used. No studies of this kind have been reported in which Chinese materials were used.

\section{METHOD}

\section{Subjects}

The sample consisted of 14 native speakers of Mandarin who were studying at the Australian National University. All had normal or corrected-to-normal vision.

\section{Stimulus Material for Compound Characters}

In the compound character condition, there were five types of foil. Examples of the five foil types created for the exemplar fox are presented in Table 1 . The first type was visually similar and phonologically identical (in both sound and tone) to the exemplar $(\mathrm{V}+\mathrm{P}+)$. The second type was visually similar, but phonologically dissimilar to the exemplar $(\mathrm{V}+\mathrm{P}-)$. The first two types of foil had the same phonetic component as that of the target exemplar. The third foil type was also visually similar but phonologically dissimilar to the exemplar $\left(\mathrm{V}_{\mathrm{R}}+\mathrm{P}-\right)$. The visual similarity, however, arose from the sharing of the radical component. The fourth type of foil was phonologically identical but visually dissimilar to the target exemplar $(\mathrm{V}-\mathrm{P}+)$. The last foil type was both visually and phonologically dissimilar to the target exemplar $(\mathrm{V}-\mathrm{P}-)$. The five types of foil, therefore, differed from each other and from the target exemplar in the following ways: (1) whether or not they sounded alike, (2) whether or not they had the same phonetic component as that of the target exemplar, and (3) whether or not they had the same radical component as that of the target exemplar.

Ten semantic categories (animal, building, body part, fruit, plant, fuel, cloth material, emotion, area with water, and action) were selected. A member of each of the 10 categories was then chosen as a target exemplar. For each exemplar, one foil for each of the five foil types was prepared. There were therefore 10 target exemplars and 50 foils altogether. The entire stimulus set is shown in Appendix A.

In a typical trial, the subject would see a semantic category name first, followed by a stimulus. The stimulus could be a foil, a target exemplar, or a filler (defined below), and the subject's task was to decide whether or not the stimulus was a member of the semantic category presented before. When a target exemplar was presented, the subject's response should have been "yes" (e.g., fox, for the category of animal). Since there were 10 target exemplars, there were 10 "yes" responses. When any one of the five foils of a target exemplar was presented, the correct response should have been "no," because none of these foils were members of the designated semantic category. Four of these five foils (Foils 1-4, Table 1) were not members of the category, although each of them was similar in some way to the target exemplar. The fifth foil (Foil 5, Table 1) was totally unrelated in meaning, sound, or appearance to the target exemplar, but was included to provide a baseline for the latency to reject a negative exemplar of a semantic category. Because character frequency may affect the speed in which a foil is rejected as an exemplar of a category, foil frequencies were matched as closely as possible across all five foil types (see the bottom row of Table 1). Frequency counts of these foils were based on information given by the Beijing Institute of Language (1986). Pairwise comparisons revealed that these means were not significantly different from each other (all $p \mathrm{~s}>.05$ ).

Since there were 10 target exemplars and 50 foils, there should have been 10 "yes" and 50 "no" responses to these stimuli. In order to equate the number of "yes" and "no" responses in the experiment, 10 "no" fillers' and 50 "yes" fillers were prepared. These fillers were negative and positive exemplars of the same 10 semantic categories that were used to select target exemplars and foils. All "yes" fillers were selected with the constraint that no two fillers of the same category could have the same radical component. This was necessary to prevent subjects from using the radical component as a cue for guessing that a stimulus was a member of a particular category.

\section{Stimulus Materials for Integrated Characters}

In the case of integrated characters, because there was no meaningful way of separating a character into components, only three foils for a particular target exemplar were possible. I Examples of the three foil types for the exemplar rabbit are shown in Table 2. The three foil types varied along the visual and phonological similarity dimensions. The first type of foil was visually similar but phonologically dissimilar to the exemplar $(\mathrm{V}+\mathrm{P}-)$. The second was visually dissimilar but phonologically identical (both in sound and in tone) to the exemplar $(\mathrm{V}-\mathrm{P}+)$. The third was both visually and phonologically dissimilar to the exemplar $(\mathrm{V}-\mathrm{P}-)$.

Table 1

Examples of the Five Foil Types Employed in the Compound Character Condition of the Semantic Categorization Task, With Mean Character Frequency (Number of Occurrences per Million) for Each Type of Foil

\begin{tabular}{|c|c|c|c|c|c|c|}
\hline \multirow{2}{*}{$\begin{array}{l}\text { Semantic } \\
\text { Category }\end{array}$} & \multirow{2}{*}{$\begin{array}{c}\text { Categorical } \\
\text { Exemplar }\end{array}$} & \multicolumn{5}{|c|}{ Foil Type } \\
\hline & & $\mathrm{V}+\mathrm{P}+$ & $\mathrm{V}+\mathrm{P}-$ & $\overline{V_{R}+P-}$ & $\mathrm{V}-\mathrm{P}+$ & $\mathrm{V}-\mathrm{P}-$ \\
\hline An animal & 佩 & 胧 & 呱 & 猜 & 湖 & 愣 \\
\hline Phonology & hu & hu & gua & cai & hu & leng \\
\hline Meaning & fox & curve & making noise & guess & lake & distracted \\
\hline Mean frequency & & 97.4 & 101.4 & 100.8 & 99.6 & 99.6 \\
\hline
\end{tabular}

Note- $\mathrm{V}+\mathrm{P}+$, visually similar, phonologically identical to the target exemplar; $\mathrm{V}+\mathrm{P}-$, visually similar, phonologically dissimilar to the target exemplar. Both $\mathrm{V}+\mathrm{P}+$ and $\mathrm{V}+\mathrm{P}-$ shared the same phonetic component as that of the target exemplar. $\mathrm{V}_{\mathrm{R}}+\mathrm{P}-$, visually similar, phonologically dissimilar to the target exemplar, but visual similarity due to sharing of same radical component. $\mathrm{V}-\mathrm{P}+$, visually dissimilar, phonologically identical to the target exemplar; $\mathrm{V}-\mathrm{P}-$, visually dissimilar, phonologically dissimilar to the target exemplar. 
Table 2

Examples of Foil Types Employed in the Integrated Character Condition of the Semantic Categorization Task, With Mean Character Frequency (Number of Occurrences per Million) for Each Type of Foil

\begin{tabular}{lcccc}
\hline \multirow{2}{*}{$\begin{array}{c}\text { Semantic } \\
\text { Category }\end{array}$} & Categorical & \multicolumn{3}{c}{ Foil Type } \\
\cline { 3 - 5 } Exemplar & $\mathrm{V}+\mathrm{P}-$ & $\mathrm{V}-\mathrm{P}+$ & $\mathrm{V}-\mathrm{P}-$ \\
\hline An animal & 兔 & 免 & 叫 & 慨 \\
Phonology & tu & mian & tu & kai \\
Meaning & rabbit & exempt & vomit & touched \\
Mean frequency & & 104.7 & 97.5 & 125.7 \\
\hline
\end{tabular}

Note- $-\mathrm{V}+\mathrm{P}-$, visually similar, phonologically dissimilar to the target exemplar; $\mathrm{V}-\mathrm{P}+$, visually dissimilar, phonologically identical to the target exemplar; $\mathrm{V}-\mathrm{P}-$, visually dissimilar, phonologically dissimilar to the target exemplar.

Preparation of stimulus materials for the integrated characters was identical to that for compound characters, except for the following: The 10 semantic categories included animal, plant, color name, energy, government post, number, emotion, water transport, female relatives, and male relatives. Only the first two categories were used in the compound character condition. There were three foil types for each target exemplar. This resulted in a total of 30 foils (see Appendix B). In principle, foil characters should belong to the same class as targets do (i.e., integrated or compound). This was possible for the compound character condition, in which all foils were compound characters. However, in the integrated character condition, this principle was more difficult to maintain. This is because only around $10 \%$ of Chinese characters are integrated characters. It was therefore very difficult to select an integrated character as a foil that was controlled for tone and character frequency. Of the 10 visual foils, all were integrated characters, because each foil had to be matched to the target on visual appearance. This requirement was relaxed for selection of homophonic and unrelated foils in the integrated character condition. Of the 10 homophonic foils, 5 were integrated and 5 were compound characters. In the homophonic foil condition, it was the sound of the character that was most important and visual similarity could vary. Of the unrelated foils, 3 were integrated and 7 were compound characters. In the unrelated foil condition, neither sound nor visual information was similar to that of the target. It could be argued that inclusion of compound characters in the homophonic foil condition might have biased our stimuli in favor of finding a phonological interference effect. This issue will be considered further in the Results section.

The average character frequencies of the three foil types are presented in the bottom row of Table 2. Pairwise mean comparisons showed that these means were not significantly different from each other (all $p s>.05$ ). Since there were fewer foils in the integrated character condition, the number of "yes" fillers was correspondingly reduced. In addition, another 10 "yes" fillers and 10 "no" fillers were constructed from all semantic categories used in the compound and integrated character conditions. These fillers were used as stimuli for practice.

\section{Procedure}

The experiment consisted of six blocks. The first block was a practice block, where subjects were exposed to all category names. The practice block consisted of 20 trials, 10 with stimuli that were exemplars of the semantic categories used in the study (10 "yes" fillers) and 10 with stimuli that were not (10 "no" fillers). Next came four experimental blocks. All 80 foils (50 from the compound character condition and 30 from the integrated character condition) were mixed with 80 "yes" fillers and presented in a pseudorandom order to subjects so that no items from the same category were presented consecutively. There were 40 trials in each block. The order of presentation of the four blocks was counterbalanced across subjects. The last block was a control block to verify that subjects correctly categorized target exemplars as belonging to their respective categories. The control block consisted of the same 20 target exemplars ("yes" responses) that were used in the experimental trials and 20 "no" fillers. These stimuli were presented in a pseudorandom order to the subjects. The subjects rested for 2 min between each block of trials.

The subjects were tested individually. Stimulus characters were presented on the screen of a Macintosh LC microcomputer. The subjects were told that they would see a category name, followed by a fixation point. A character would then appear at the position of the fixation point. The subject's task was to decide (by keypressing) as quickly as possible whether or not the character was a member of the designated semantic category. Two keys on the keyboard were selected for responding: the "ctrl" key and the "." key. The assignment of "yes" and "no" responses to the two keys was counterbalanced between subjects. If they did not know the meaning of the character, they were asked to press the space bar. The "yes," "no," and "do not know" responses, as well as the subjects' reaction times, were recorded by the computer.

A typical trial in the experiment began with the presentation of a category name for $1.5 \mathrm{sec}$. This was followed by the fixation point, which appeared below the category name and remained on display for $100 \mathrm{msec}$. There was then a 400 -msec interval when the screen was blank. A target character then appeared at the position of the fixation point. The character remained on the screen until the subject made a response. Once the response was made, an auditory tone signaled to the subject that the next trial was about to begin. The intertrial interval was $1.5 \mathrm{sec}$.

\section{RESULTS}

Data were analyzed in two analyses of variance (ANOVAs). In the first ANOVA, subjects were treated as a random factor, in order to assess whether any effect obtained with the use of the current stimulus materials was consistent across the subject population. In the second ANOVA, stimulus items were a random factor. This was done to further generalize any significant findings beyond the use of the specific stimuli chosen for the present experiment (Clark, 1973). The Greenhouse-Geisser criterion was used to test all effects. Although the ANOVA technique is normally considered quite robust to violations of the homogeneity of variance assumption (Kirk, 1982), all data were screened by using Hartley's $F_{\max }$ procedure (evaluated at a significance level of .01) prior to the actual statistical analyses. Where significant violation of the assumption was found, the analysis was conducted on transformed data.

The data analysis was conducted on the foils only. However, only foils whose matched target exemplars were correctly classified were included in the analysis. A false positive error was noted if the subject pressed "yes" when the correct response should have been "no." ("Do not know" responses accounted for less than $1 \%$ of the data and were not included in the analysis.)

\section{Compound Characters}

Latencies. Figure 1 shows the average latencies taken to reject foils, which shared varying degrees of visual and phonological similarity with their respective target 


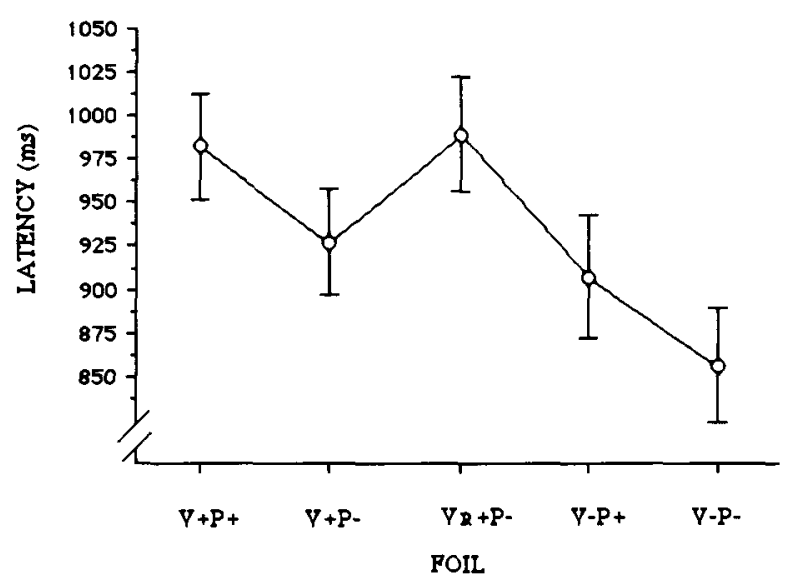

Figure 1. Mean latencies and standard errors of semantic category judgments for five foil types of compound characters. The foil types differ from their target exemplars in the following ways: Foil 1, V+P+, visually similar (phonetic component) and phonologically identical; Foil 2, V+P-, visually similar (phonetic component) and phonologically dissimilar; Foil $3, V_{R}+P-$, visually similar (radical component) and phonologically dissimilar; Foil $4, V-P+$, visually dissimilar and phonologically identical; Foil $5, \mathrm{~V}-\mathrm{P}-$, visually dissimilar and phonologically dissimilar (unrelated).

exemplars. A one-way ANOVA revealed that the main effect for foil type was significant by subjects $[F(4,52)=$ $7.09, p<.01]$ and by items $[F(4,45)=2.84, p<.05]$. A Dunnett's test, which allowed multiple comparisons to be made against a baseline, was performed on every type of foil. This enabled us to assess the effects that visual and/or phonological similarity to an exemplar of a semantic category had on the time taken to reject a foil. The baseline was a foil that was totally unrelated to its exemplar in meaning, form, or sound. Results of the Dunnett's test showed that subjects took longer to reject Foils $1(\mathrm{~V}+\mathrm{P}+)$, $2(\mathrm{~V}+\mathrm{P}-)$, and $3\left(\mathrm{~V}_{\mathrm{R}}+\mathrm{P}-\right)$ than to reject the baseline foil, but took no longer to reject Foil $4(\mathrm{~V}-\mathrm{P}+)(\alpha=.05$ in subject and item analyses). The one exception to this was Foil 2 in comparison with baseline, which was only significant in the subject analysis. Another contrast was carried out between Foil $2(\mathrm{~V}+\mathrm{P}-)$ and Foil $3\left(\mathrm{~V}_{\mathrm{R}}+\mathrm{P}-\right)$ to compare the effect of two types of visual similarity to the target exemplar. Foil 2 had the same phonetic component while Foil 3 had the same radical component as that of the target exemplar. There was a significant difference in response latency between the two foils $[F(1,52)$ $=4.50, p<.05$ ] by subjects but not by items.

The phonological and visual interference effects of the phonetic component of compound characters were examined by comparing target-foil visual similarity and targetfoil phonological similarity in a two-way repeated measures ANOVA. The results are summarized in Figure 2. There were significant effects of visual similarity $[F(1,13)$ $=12.26, p<.01]$ and phonological similarity $[F(1,13)=$ $7.55, p<.02]$, but no interaction between visual and phonological similarity $[F(1,13)=0.009, p>.05]$.

Errors. The percentages of false positive errors for the different kinds of foil are shown in Table 3 . The error data were skewed and accordingly were arcsine transformed before further analysis was conducted (Winer, 1971). A one-way ANOVA showed that the error rates for the five foil types did not significantly differ from each other $[F(4,52)=1.41, p>.05$, by subjects, and $F(4,45)=1.02$, $p>.05$, by items].

\section{Integrated Characters}

Latencies. The average latencies for correctly rejecting foils that were visually similar, phonologically similar, or unrelated to a target exemplar are shown in Figure 3. A one-way ANOVA of the latency data revealed a significant main effect for foil type $[F(2,26)=11.15$, $p<.01$, by subjects, and $F(2,27)=4.68, p<.02$ by items]. Post hoc multiple comparisons using the Dunnett's test showed that subjects took significantly longer to reject a visually similar foil $(1,034.5 \mathrm{msec})$ as opposed to an unrelated baseline foil $(852.4 \mathrm{msec})(p<.01$ by subjects, $p<.05$ by items). The difference in response latency between a homophonic foil and an unrelated foil was not significant.

We investigated differences between mean reaction times for compound and integrated characters in the homophonic foil condition because of the concern that the inclusion of compound characters might have biased our stimuli in favor of the finding of a phonological interference effect. Mean reaction times were, for compound characters, $856.0 \mathrm{msec}$, and for integrated characters, $957.3 \mathrm{msec}$. This difference was significant $[t(13)=$ $3.94, p>.01]$.

Errors. Table 3 also shows the mean error rates for the three foil types. The error rate was $25.7 \%$ when the foil was visually similar to the target; it was $2.8 \%$ when the foil sounded similar to the target. A one-way ANOVA performed on the arcsine transformed data showed that the foil main effect was highly significant $[F(2,26)=40.43$, $p<.01$, by subjects, and $F(2,27)=8.38, p<.01$, by items]. Post hoc multiple comparisons by the Dunnett's test showed that the false positive error rate of visually similar foils was significantly different from that of unrelated foils $(p<.01)$. The error rates of phonologically similar and unrelated foils were not significantly different.

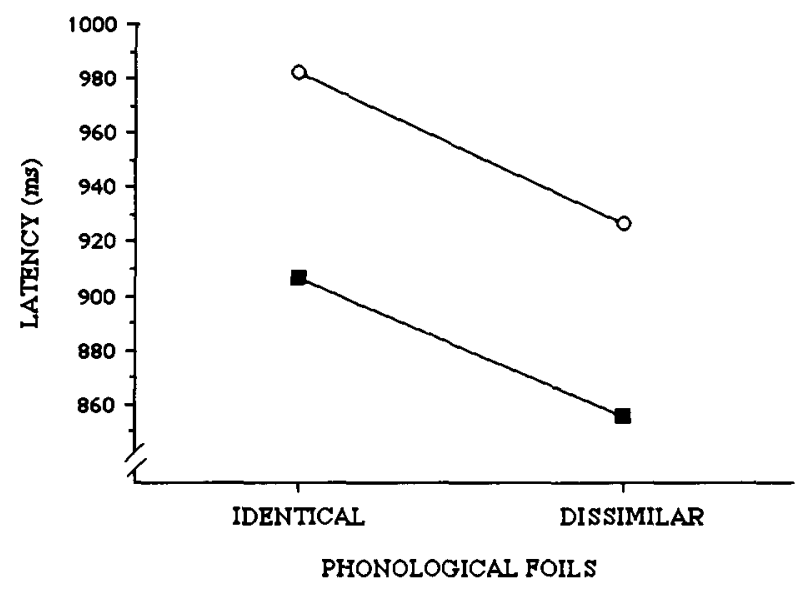

Figure 2. Mean latencies of semantic category judgments for different types of visual and phonological foils for compound characters. 
Table 3

False Positive Error Rates (in Percent) for Five Foil Types of Compound Characters and for Three Foil Types of Integrated Characters*

\begin{tabular}{|c|c|c|}
\hline \multirow[b]{2}{*}{ Foil Type } & \multicolumn{2}{|c|}{ Error Rate } \\
\hline & $\begin{array}{l}\text { Compound } \\
\text { Characters }\end{array}$ & $\begin{array}{l}\text { Integrated } \\
\text { Characters }\end{array}$ \\
\hline $\begin{array}{l}\text { Visually similar (phonetic), } \\
\text { phonologically identical }\end{array}$ & 5.0 & \\
\hline $\begin{array}{l}\text { Visually similar (phonetic), } \\
\text { phonologically dissimilar }\end{array}$ & 1.4 & \\
\hline $\begin{array}{l}\text { Visually similar (radical), } \\
\text { phonologically dissimilar }\end{array}$ & 6.4 & $25.7^{*}$ \\
\hline $\begin{array}{l}\text { Visually dissimilar, } \\
\text { phonologically identical }\end{array}$ & 5.0 & 2.8 \\
\hline $\begin{array}{l}\text { Visually dissimilar, } \\
\text { phonologically dissimilar } \\
\text { (unrelated baseline) }\end{array}$ & 1.4 & 0.7 \\
\hline
\end{tabular}

The exceptionally high proportion of visual errors $(25.7 \%)$ suggests that the effect might have been due to subjects' strategies. This hypothesis was assessed by comparing the latencies of correct and incorrect responses. First, a point biserial correlation between subjects' response accuracy and latency to foils was computed and the correlation was not significant $\left(r_{p b}=.013, p>.05\right)$. This result suggests that the high error rate of visual foils is not due to a speed-accuracy tradeoff strategy. False positives ( $M=998.8 \mathrm{msec})$ took just as long to make as correct rejections $[M=1,034.5 \mathrm{msec} ; t(136)=.14, p>$ .05]. Second, the latencies of false positives were also compared with the latencies of correct "yes" responses. If subjects had merely misidentified the visual foils (e.g., 兔) for the targets (e.g., 兔), the mean time for responding "yes" to a foil should not have been different from the mean time taken to respond "yes" to a "yes" filler. However, the contrary was found to be the case. False positive "yes" responses $(M=998.8 \mathrm{msec})$ took significantly longer time to make than did the correct "yes" responses $(M=820.2 \mathrm{msec} ; t=2.16, p<.05)$.

\section{DISCUSSION}

For integrated characters, the finding that subjects were significantly slower and made more errors in rejecting a visually similar foil than they did when rejecting an unrelated foil suggests that visual information is very important for the processing of integrated characters. This high error rate is not the result of a speed-accuracy tradeoff. Furthermore, the time taken to make such false positive errors was found to be significantly longer than the time required to respond "yes" to a "yes" filler trial. This finding indicates that subjects did not merely misidentify a visually similar foil as its target exemplar; rather, when a visually similar foil was presented, it activated not only its own mental representation in the lexicon, but also that of its exemplar. The consequent need to decide between the two competing representations for the identity of the stimulus character results in more time devoted to its processing. Depending on the basal activation level of the two representations (this is dependent on factors such as character frequency, contextual cue, etc.), one representation might reach activation threshold faster than the other, resulting in either a false or a correct identification. This explanation accounts for the longer period of time needed to make either a false positive or a correct rejection response. It also explains the very high false positive error rate (since the semantic category that had just been presented provided a strong contextual cue for elevating the basal activation level of the target exemplar). The evidence presented here therefore strongly suggests that the mental representation of an integrated character is activated predominantly by the visual information contained in the character. We found no effect of phonological interference on recognition of integrated characters even though some of our homophonic foil stimuli contained an extra phonetic component which thus biased our results in favor of the finding of such an effect.

Evidence in support of the claim that phonology is important in the processing of Chinese characters is prevalent in the literature (e.g., Cheng \& Shih, 1988; Lam, Perfetti, \& Bell, 1991; Perfetti \& Zhang, 1991, in press; Perfetti, Zhang, \& Berent, 1992). This evidence is limited, however, because of the confound that the majority of stimuli used in these studies are compound characters. Perfetti and Zhang (in press) have found that phonological similarity (homophony) interferes with the judgment that two characters have different meanings. Furthermore, phonological processes appear to be not only a part of Chinese reading but an automatic part that accompanies lexical processing. Wydell, Patterson, and Humphreys (1993) found that Japanese subjects made more semantic category judgment errors with homophones in kanji and also found a significant effect of visual similaritythat is, incorrect target words that were visually similar to correct exemplars of the category names yielded longer reaction times and higher error rates. In their study, however, the effect of visual similarity could have been due simply to priming because the target and foil

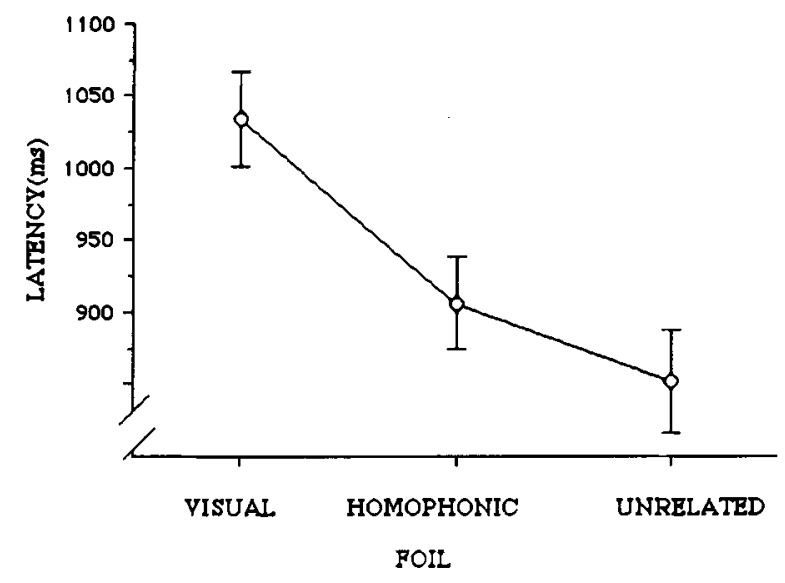

Figure 3. Mean latencies and standard errors of semantic category judgments for three foil types for integrated characters. 
contained exactly the same character. This possibility was excluded in our study, because we matched character components rather than whole characters when creating the target-foil pairs. Although Perfetti and Zhang (in press) and Wydell et al. (1993) used integrated and compound characters, the majority of these characters were compound. Therefore the effects of visual and phonological information on the processing of these characters were not examined separately. Phonological information was used in processing the compound characters in our study. However, our data suggest that if integrated characters are included when one is examining Chinese character recognition, the contribution of phonology will be underestimated.

The finding with compound characters that subjects take longer to reject a foil, but only when it is visually similar and phonologically identical to its target exemplar, is significant. For these characters, subjects took significantly longer time than they did for an unrelated foil to reject two types of foil: a phonologically identical and visually similar foil $(\mathrm{V}+\mathrm{P}+)$ and a foil that had the same radical component as that of its target exemplar $\left(\mathrm{V}_{\mathrm{R}}+\mathrm{P}-\right)$. This suggests that both visual and phonological information are employed in the processing of a compound character (and not just the visual or the phonological information alone).

The results from the one-way ANOVA showed significant interference for all foils except Foil $4(\mathrm{~V}-\mathrm{P}+)$. To evaluate the relative contributions to these interference effects of visual and phonological similarity further, we examined these variables in a $2 \times 2$ design. The results showed strong and independent visual and phonological interference effects. This is evidence in support of the claim that both visual and phonological information are processed in the case of the compound characters.

There was also evidence that the radical component, which is a unique feature of Chinese compound characters, significantly impedes the time taken to make semantic judgments about a compound character. This demonstrates that the radical component is very important for retrieving the meaning of a compound character. However, this finding cannot be taken as evidence that compound characters are necessarily processed visually. There are two reasons for this. First, although Foil 3 (猜) contains the same radical component as does the target exemplar (狐), making it visually similar but phonologically dissimilar to the exemplar, the visual similarity is no greater than the visual similarity between another foil (Foil 2, 呱) that contains the same phonetic component as do its target exemplar (狐) and the target exemplar. If visual similarity between a foil and a target exemplar is mainly responsible for the delay in response latency, then both foils (猜 and 呱) should cause similar delay in the rejection of the foils. The fact that only Foil 3 showed a longer delay in response latency suggests that the effect of a radical component on the lexical access of a compound character is not purely visual. The second point is that a radical serves as a cue for the entire semantic category that it belongs to, rather than the specific target exemplar from which it is constructed. This is because a radical component is common to many exemplars within that particular semantic category. The animal category, for example, has many exemplars with as a radical: 狼, 诋, 狮, 狗, 㺕 (wolf, fox, lion, dog, cat). A similar example from English is the prefix anti in antidote as a cue for the category against or opposite something. Given that such prefixes are semantic cues for an entire category, the results suggest that the radical component could be more than just a visual cue. That is, it is translated into semantic information that activates the mental representation of a compound character. This idea is also supported by findings of another study, conducted by Chen, Yung, and $\mathrm{Ng}$ (1988). In this study, subjects were asked to perform a lexical decision task with compound and pseudocharacters. The stimulus was preceded by either a radical component or a phonetic component of a compound character as a cue. The pseudocharacter would be a character-like stimulus which contained either the same radical component as a real character or the phonological component of the same character. The response to any pseudocharacter should be "no," because it is not a real character. Chen et al. (1988) found that the presentation of a radical cue significantly prolonged the time taken for subjects to decide that a pseudocharacter which contained the radical was not a real character, in comparison with the case in which its phonetic component was presented as a cue. Furthermore, the error rate in the radical cue condition was also higher, showing that subjects were more likely to consider a pseudocharacter as a real character when it was preceded by a radical component. Chen et al.'s (1988) findings, together with the present data, suggest that, when one is processing a compound Chinese character, radical information plays a role in lexical access additional to visual and phonological information. One way to investigate the existence of an independent radical reading route would be to examine data from acquired dyslexic patients in Chinese, as has been done with English dyslexic patients (Weekes \& Coltheart, in press).

The present study has shown that visual information is used in the processing of Chinese characters. The importance of phonological information in Chinese character recognition has also been confirmed, but only for compound characters. Furthermore, a radical route to lexical access for Chinese compound characters may be possible. All words (or characters in Chinese) are primarily visual patterns, but different orthographies may differ in the ways in which the constituent components are mapped into sound and meaning. The results of the present study suggest that these components are all important in lexical access and that the difficulty in finding evidence for a direct visual process may be a specific consequence of employing English words which confound spelling and pronunciation. This is seen most clearly in the null effect of phonology on the processing of integrated characters. 


\section{REFERENCES}

Beijing Institute of Language (1986). Modern Chinese frequency dictionary. Beijing Institute of Language Press.

Biederman, I., \& TsaO, Y.-C. (1979). On processing Chinese ideographs and English words: Some implications from Stroop-test results. Cognitive Psychology, 11, 125-132.

Chen, M. J., Yung, Y. F., \& NG, T. W. (1988). The effect of context on perception of Chinese characters. In I. M. Liu, H. C. Chen, \& M. J. Chen (Eds.), Cognitive aspects of the Chinese language (Vol. 1, pp. 27-39). Hong Kong: Asian Research Service.

Cheng, C.-M., \& Shih, S.-I. (1988). The nature of lexical access in Chinese: Evidence from experiments on visual and phonological priming in lexical judgement. In I. M. Liu, H. C. Chen, \& M. J. Chen (Eds.), Cognitive aspects of the Chinese language (Vol. 1, pp. 1-14). Hong Kong: Asian Research Service.

Clark, H. H. (1973). The language as fixed effect fallacy: A critique of language statistics in psychological research. Journal of Verbal Learning \& Verbal Behaviour, 12, 335-359.

Coltheart, M. (1978). Lexical access in simple reading tasks. In G. Underwood (Ed.), Strategies of information processing (pp. 151216). New York: Academic Press.

Coltheart, M., Curtis, B., \& ATKINs, P. (1993). Models of reading aloud: Dual route and parallel distributed processing approaches. Manuscript submitted for publication.

KIRK, R. E. (1982). Experimental design: Procedure for the behavioral sciences (2nd ed.). Belmont, CA: Brooks/Cole.

Lam, A. S., Perfetti, C. A., \& Bell, L. (1991). Automatic phonetic transfer in bidialectal reading. Applied Psycholinguistics, 12, 299-311.

LI, H. T. (1977). The history of Chinese characters. Taipei: Lian-Jian.

Lukatela, G., Lukatela, K., \& Turvey, M. T. (1993). Further evidence for phonological constraints on visual lexical access: TOWED primes FROG. Perception \& Psychophysics, 53, 461-466.

PAAP, K. R., \& NoEL, R. W. (1991). Dual-route models of print to sound: Still a good horse race. Psychological Research, 53, 13-24.

Perfetti, C. A., \& Zhang, S.-L. (1991). Phonological processes in reading Chinese characters. Journal of Experimental Psychology: Learning, Memory, \& Cognition, 17, 633-643.

Perfetti, C. A., \& Zhang, S.-L. (in press). Very early phonological activation in Chinese reading. Journal of Experimental Psychology: Learning, Memory, \& Cognition.
Perfetti, C. A., Zhang, S.-L., \& Berent, I. (1992). Reading in English and Chinese: Evidence for a "universal" phonological principle. In R. Frost \& L. Katz (Eds.) Orthography, phonology, morphology, and meaning (pp. 227-248). Amsterdam: Elsevier.

SEIDENBERG, M. S. (1985). The time course of phonological code activation in two writing systems. Cognition, 19, 1-30.

SeidenberG, M. S., \& MCClelland, J. L. (1989). A distributed developmental model of word recognition and naming. Psychological Review, 96, 523-568.

TAFT, M. (1991). Reading and the mental lexicon. Hove, U.K.: Erlbaum.

TZENG, O. J. L., \& HuNG, D. L. (1988). Cerebral organization: Clues from scriptal effects on lateralization. In I. M. Liu, H. C. Chen, \& M. J. Chen (Eds.), Cognitive aspects of the Chinese language (Vol. 1, pp. 119-139). Hong Kong: Asian Research Service.

VAN ORdEN, G. C. (1987). A ROWS is a ROSE: Spelling, sound, and reading. Memory \& Cognition, 15, 181-198.

VAN ORden, G. C., Johnston, J. C., \& Hale, B. L. (1988). Word identification in reading proceeds from spelling to sound to meaning. Journal of Experimental Psychology: Learning, Memory, \& Cognition, 14, 371-385.

Van Orden, G. C., Pennington, B. F., \& Stone, G. O. (1990). Word identification in reading and the promise of subsymbolic psycholinguistics. Psychological Review, 97, 488-522.

WeEKES, B., \& COLTHEART, M. (in press). Rehabilitation of acquired surface dyslexia and acquired surface dysgraphia: Treatment studies and their theoretical implications. Cognitive Neuropsychology.

WINER, B. J. (1971). Statistical principles in experimental design (2nd ed.). New York: McGraw-Hill.

Wydell, T. N., Patterson, K. E., \& Humphreys, G. W. (1993). Phonologically mediated access to meaning for Kanji: Is a rows still a rose in Japanese Kanji? Journal of Experimental Psychology, 19, 491-514.

YIN, W. (1991). On reading Chinese characters-An experimental and neuropsychological study. Unpublished doctoral dissertation, University of London.

\section{NOTE}

1. In the integrated character condition, no distinction was made between phonological similarity and radical similarity to target exemplars. Only one type of foil was visually similar and phonologically dissimilar to the target exemplar.

\section{APPENDIX A}

Compound Characters Used in the Semantic Categorization Experiment

\begin{tabular}{|c|c|c|c|c|c|c|}
\hline $\begin{array}{l}\text { Semantic } \\
\text { Category }\end{array}$ & $\begin{array}{c}\text { Target } \\
\text { Exemplar }\end{array}$ & $\begin{array}{c}\text { Visually similar } \\
\text { (phonetic) } \\
\text { Phonologically } \\
\text { identical } \\
\end{array}$ & $\begin{array}{c}\text { Visually similar } \\
\text { (phonetic) } \\
\text { Phonologically } \\
\text { dissimilar }\end{array}$ & $\begin{array}{c}\text { Visually similar } \\
\text { (radical) } \\
\text { Phonologically } \\
\text { dissimilar }\end{array}$ & $\begin{array}{c}\text { Visually dissimilar } \\
\begin{array}{c}\text { Phonologically } \\
\text { identical }\end{array}\end{array}$ & $\begin{array}{c}\text { Visually dissimilar } \\
\text { Phonologically } \\
\text { dissimilar } \\
\text { (unrelated) } \\
\end{array}$ \\
\hline Animal & 狐 & $\begin{array}{l}\text { 弧 } \\
\text { curve }\end{array}$ & $\begin{array}{c}\text { 呱 } \\
\text { making noise }\end{array}$ & $\begin{array}{c}\text { 猜 } \\
\text { guess }\end{array}$ & $\begin{array}{l}\text { 湖 } \\
\text { lake }\end{array}$ & $\begin{array}{c}\text { 愣 } \\
\text { distracted }\end{array}$ \\
\hline Building & 寅 & 遇 & 偶 & 宏 & 欲 & 渏 \\
\hline Body part & 肝 & 杆 & 奸 & 脆 & 柑 & 栗 \\
\hline Fruit & 桃 & 逃 & 眺 & 析 & 陶 & 烛 \\
\hline Plant & 蕉 & 礁 & 睢 & 荐 & 骄 & 派 \\
\hline Fuel & 煤 & 媒 & 谋 & 烂 & 霎 & 痘 \\
\hline Cloth Material & 绸 & 稠 & 调 & 绊 & 仇 & 檐 \\
\hline
\end{tabular}


APPENDIX A (Continued)

Compound Characters Used in the Semantic Categorization Experiment

\begin{tabular}{|c|c|c|c|c|c|c|}
\hline $\begin{array}{l}\text { Semantic } \\
\text { Category }\end{array}$ & $\begin{array}{c}\text { Target } \\
\text { Exemplar }\end{array}$ & $\begin{array}{l}\text { Visually similar } \\
\text { (phonetic) } \\
\text { Phonologically } \\
\text { identical }\end{array}$ & $\begin{array}{l}\text { Visually similar } \\
\text { (phonetic) } \\
\text { Phonologically } \\
\text { dissimilar }\end{array}$ & $\begin{array}{c}\text { Visually similar } \\
\text { (radical) } \\
\text { Phonologically } \\
\text { dissimilar }\end{array}$ & $\begin{array}{c}\begin{array}{c}\text { Visually dissimilar } \\
\text { Phonologically } \\
\text { identical }\end{array} \\
\end{array}$ & $\begin{array}{c}\text { Visually dissimilar } \\
\text { Phonologically } \\
\text { dissimilar } \\
\text { (unrelated) } \\
\end{array}$ \\
\hline Cloth Material & 细 & 稠 & 调 & 绊 & 仇 & 檐 \\
\hline Emotion & 悦 & 阅 & 脱 & 恰 & 岳 & 蜡 \\
\hline Area with water & 洋 & 佯 & 祥 & 沿 & 杨 & 剪 \\
\hline Action & 挥 & 辉 & 浑 & 擅 & 灰 & 茎 \\
\hline
\end{tabular}

APPENDIX B

Integrated Characters Used in the Semantic Categorization Experiment

\begin{tabular}{|c|c|c|c|c|}
\hline $\begin{array}{l}\text { Semantic } \\
\text { Category }\end{array}$ & $\begin{array}{c}\text { Target } \\
\text { Exemplar }\end{array}$ & $\begin{array}{c}\text { Visually similar } \\
\text { Phonologically } \\
\text { dissimilar } \\
\text { (Visual foil) }\end{array}$ & $\begin{array}{l}\text { Visually dissimilar } \\
\text { Phonologically } \\
\text { identical } \\
\text { (Homophonic foil) }\end{array}$ & $\begin{array}{l}\text { Visually dissimilar } \\
\text { Phonologically } \\
\text { dissimilar } \\
\text { (Unrelated foil) }\end{array}$ \\
\hline Animal & $\begin{array}{c}\text { 兔 } \\
\text { rabbit }\end{array}$ & 免 & $\underset{\text { vomit }}{\text { 叫 }}$ & $\begin{array}{c}\text { 慨 } \\
\text { touched }\end{array}$ \\
\hline Color & 赤 & 永 & 斥 & 鹅 \\
\hline Energy & 电 & 龟 & 奠 & 陈 \\
\hline Government post & 區 & 巨 & 辰 & 籍 \\
\hline Number & 五 & 丹 & 舞 & 凸 \\
\hline Emotion & 衣 & 衰 & 埃 & 裙 \\
\hline Plant & 瓜 & $\pi$ & 刮 & 及 \\
\hline Water transport & 舟 & 丹 & 州 & 槛 \\
\hline Relative (female) & 母 & 冓 & 亩 & 鸣 \\
\hline Relative (male) & 兄 & 克 & 胸 & 巾 \\
\hline
\end{tabular}

(Manuscript received December 22, 1993;

revision accepted for publication August 9,1994 .) 